Área Abierta. Revista de comunicación

audiovisual y publicitaria

ISSN: 2530-7592 / ISSNe: 1578-8393

\title{
La construcción cultural del asesino en serie en el cine de terror (1960- 1980): Michael Myers y Samuel Loomis en La noche de Halloween (1978)
}

\author{
Erika Tiburcio Moreno ${ }^{1}$
}

Recibido: 31 de marzo de 2020 / Aceptado: 4 de junio de 2020

Resumen. El asesino en serie no puede ser entendido únicamente como una categorización criminológica sino también como un constructo discursivo necesario para mantener el orden social. Su monstruosidad en el cine de terror y en los medios ha servido para reforzar la labor de salvaguardar la "pureza" normativa por parte del psiquiatra/criminólogo. La metodología seguida se ha basado en la interdisciplinariedad de los estudios culturales y, en particular, en el análisis fílmico e histórico del periodo. Además, la muestra de setenta películas analizadas en este estudio nos ha permitido observar la existencia de una serie de tendencias. Entre los principales resultados, cabe destacar la similitud de la monstruosidad y la normalidad en relación con la ordenación jerárquica de las categorías mentales. Palabras clave: Asesino en serie; Cine de terror; Estudios culturales; Estados Unidos; Siglo XX; Historia

\section{[en] The Cultural Construction of the Serial Killer in Horror Film (1960- 1980): Michael Myers and Samuel Loomis in Halloween (1978)}

\begin{abstract}
The serial killer cannot only be understood as a criminological classification. It is also a necessary discursive construct in order to maintain the social order. Their monstrosity has served to reinforce the role of the psychiatrist/criminologist in protecting society. Our analysis is based on cultural studies methodology and interdisciplinarity, as well as on film studies and history from the period in question. Furthermore, the sample of seventy titles analyzed in the present work has enabled us to observe the existence of several narrative trends. Amongst the main results, it is noteworthy that monstrosity is based on the same hierarchical order as the hegemonic normalcy.
\end{abstract}

Keywords: Serial Killer; Horror Cinema; Cultural Studies; United States; $20^{\text {th }}$ Century; History

Sumario. 1. Introducción. 2. Metodología. 3. La configuración criminológica del asesino en serie. 4. La construcción mediática del asesino en serie. 5. Entender el cine de terror postclásico estadounidense. 6. La creación identitaria y fílmica del asesino en serie.7. La normalidad como configuradora del asesino en serie en el cine de terror. 8. La noche de Halloween: un hito en la construcción del monstruo y del criminólogo. 9. Conclusiones. 10. Bibliografía.

Cómo citar. Tiburcio Moreno, Erika (2020). La construcción cultural del asesino en serie en el cine de terror (1960-1980): Michael Myers y Samuel Loomis en La noche de Halloween (1978). Área

Universidad Complutense de Madrid (España)

E-mail: erikatiburcio@ucm.es 
Abierta. Revista de comunicación audiovisual y publicitaria 20 (2), 191-207, http://dx.doi.org/10.5209/ arab.68578

\section{Introducción}

El asesino en serie es un monstruo paradigmático de la segunda mitad del siglo XX, creado sobre la oposición a la sociedad de la razón. En torno a esta figura se constituyó un discurso "híbrido" en el que confluyeron relatos de diversa procedencia, a saber, la psicología y la psiquiatría, los medios de comunicación y el cine popular. Se trata de una construcción cultural que hunde sus raíces en la civilización estadounidense y en la importancia de la frontera como elemento separador de lo sano/ civilizado y lo insano/salvaje. "La ordenación jerárquica de las categorías se consiguió gracias a la pervivencia de un sistema sustentado en las verdades objetivas y en la autoridad del sujeto científico" (Foucault, 1979). Además, la importancia de la frontera en la cultura estadounidense permitió trasladar los conceptos de bien y mal a los ámbitos de la locura y la criminalidad. La relación entre ambos espacios diferenciados resultó en una interdependencia donde la normalidad se construía en base a la otredad.

El objetivo de este artículo es analizar la construcción cultural e histórica del asesino en serie. Para ello comenzaremos examinando la configuración criminológica y mediática de este criminal. Tras repasar aspectos básicos del género de terror, nos centraremos en la construcción fílmica entre los años sesenta y los ochenta. Para ello, ha sido esencial el análisis de una muestra de setenta títulos estrenados entre 1960 y 1980. Como veremos, la monstruosidad no se presenta como un discurso homogéneo, sino que introduce categorías sociales en torno a la raza, el género o la clase. Finalmente, hemos centrado nuestra atención en La noche de Halloween ( $\mathrm{Ha}$ lloween, John Carpenter, 1978) y la mitificación del monstruo y del experto.

\section{Metodología}

Este estudio parte del estreno de Psicosis (Psycho, Alfred Hitchcock, 1960) por la presentación de un personaje que reúne las características de un asesino en serie moderno que fue capaz de reflejar las tensiones de la sociedad norteamericana (Thomson, 2009). "Desde ese momento, realidad y fantasía confluyeron en esta figura y crearon un discurso repleto de estereotipos que partía tanto de los medios de comunicación como del cine de terror" (Jenkins, 1994).

Por esta razón, nuestro objetivo es analizar su evolución desde esta película durante los sesenta y setenta y atender a cómo se construyen los significados simbólicos (Jane Stokes, 2013) tanto en el ámbito criminológico como en los medios de comunicación. Asimismo, la investigación se centra en el género de terror por su fórmula narrativa (Altman, 2000) y su disposición para tratar los miedos culturales.

El primer paso fue reunir una filmografía especializada y lo más completa posible acudiendo a bases de datos especializadas -American Film Institute, BFI collec- 
tions-. Los criterios de selección atendieron a su clasificación como terror y a la presencia de un antagonista humano que asesinase a dos víctimas como mínimo (siguiendo el criterio criminológico inicial). Posteriormente, debido a la imposibilidad de acceder a todos los títulos, se procedió al visionado de las que estaban disponibles con el objetivo de comprobar la clasificación inicial y establecer las categorías predominantes en el monstruo -clase, género y orientación sexual, nacionalidad y etnia, lugar de origen, perfil profesional, vestimenta y armas distintivas, razones de comportamiento, final-, el número y género de las víctimas y la presencia de expertos: psicólogos o psiquiatras y policías.

Los resultados de esta investigación fueron planteados en una tesis doctoral y publicados en una monografía actualizada y dedicada a esta figura (Tiburcio, 2019). En líneas generales, pudimos comprobar cómo este criminal, a pesar de haber conformado un perfil criminológico, muestra una evolución y refleja unas características que detallaremos a continuación.

\section{La configuración criminológica del asesino en serie}

El término serial killer/murder o asesino en serie trascendió el discurso criminológico y alcanzó la esfera social, mediática y cinematográfica. Aunque previamente habían aparecido figuras como Jack el Destripador o H.H. Holmes, fue entre los sesenta y los ochenta en Estados Unidos cuando tomaron forma sus rasgos básicos. El concepto fue acuñado por Robert K. Ressler a finales de los setenta para clasificar a los hombres blancos que cometían asesinatos repetidos durante un periodo de tiempo (Ressler y Shatchman, 1992). Además, tal y como añaden Ronald M. Holmes y James de Burger (1988), la ausencia de culpa, su habilidad de camuflaje y la justificación de su comportamiento mediante su fantasía lo convertían en uno de los criminales más amenazadores del momento.

La calificación de serial o en serie sitúa como exitoso a un criminal que, al menos en dos ocasiones, ha conseguido asesinar a sus víctimas sin ser descubierto. Asimismo, "muchos asesinos en serie, particularmente los de la variedad organizada, son razonablemente brillantes. Aunque el éxito para evitar la detención y la captura puede también deberse a la cantidad excesiva de tiempo y energía que el delincuente invierte fantaseando, planeando y evaluando el crimen" (AAVV, 2013: 481)2. Su inteligencia y su empeño en conseguir sus objetivos simbolizaban la consideración estadounidense de que el trabajo continuo y el esfuerzo son las vías para alcanzar el éxito. Durante la década de los ochenta y los noventa, la incomprensión social ante unos crímenes brutales cometidos por un hombre inteligente y civilizado extendió el pánico entre los habitantes (Martín Alegre, 1997). En cambio, el delincuente rural presentaba un menor grado de amenaza al ser concebido como el resultado de su atraso, endogamia y salvajismo.

Desde una perspectiva histórica más amplia, la Ilustración encerró a la sociedad civilizada dentro de los límites de la racionalidad: la locura y otras alteridades, tal y como explica Michel Foucault (1979), quedaron relegadas a la explicación, la clasi-

\footnotetext{
"Many serial offenders, particularly of the organized variety, are reasonably bright. But success at avoiding detection and capture can also be due to the obsessive amount of time and energy the offender puts into fantasizing, planning, and evaluating the crime". (Traducción de la autora)
} 
ficación y al dominio de los poderes científico y coercitivo. El sujeto especialista fue el encargado de controlar, encerrar y categorizar a estos elementos disidentes. En el caso estadounidense, desde los cincuenta, la psicología y la psiquiatría alcanzaron una gran popularidad por ser consideradas las únicas ciencias capaces de tratar tanto problemas cotidianos de ansiedad sexual o depresión como situaciones que podían conllevar problemas mentales más serios. De hecho, la autoridad del diagnóstico psiquiátrico se convirtió en una herramienta para resolver problemas de conducta y de tipo social (Whitaker, 2002).

Durante los setenta, algunos agentes de la Agencia Federal de Investigación (FBI), entre los que se encontraban Howard Teten o Robert Ressler, comenzaron a interesarse por las posibilidades que la psicología y la psiquiatría ofrecían para la investigación de crímenes violentos. De hecho, esta institución estaba inmersa en un proceso de especialización que se materializó a través de la creación de la Universidad de Quántico (1972) y la Unidad de Ciencias del Comportamiento -posteriormente, Unidad de Análisis del Comportamiento-, dedicada a la creación de perfiles criminológicos (FBI, 2008). Tanto la clasificación como la aparición de unidades especiales sirvieron para enfatizar la peligrosidad de este delincuente.

La acuñación del término, desde una perspectiva lingüística, supuso la creación de una serie de significados simbólicos -asesinatos repetidos, desviación moral, inadaptación- (Tonkiss, 2004) que desdibujaron y deshumanizaron a los individuos incluidos en esta categoría. La inclusión de individuos tan dispares como Jack el Destripador, Henry Howard Holmes o Ted Bundy, cuyo único nexo fueron los homicidios repetidos, derivó en la superposición del término y la desaparición de los rasgos individuales en el discurso público. La penetración de imágenes estereotipadas de la cultura popular creó una imagen colectiva del asesino en serie como una homogeneidad maligna con muchos rostros.

\section{La construcción mediática del asesino en serie}

La generalización de la televisión en los hogares desde la década de los cincuenta supuso también la creciente consideración de los programas de noticias como fuente informativa fiable y rigurosa. Durante la guerra de Vietnam, la superación de la censura oficial conllevó a la emisión de actos brutales y agresivos del conflicto a través de la televisión (Vidal, 2010). La inmediatez en la difusión audiovisual y la domesticación de la violencia influyeron en el aumento de la violencia gráfica. Posteriormente, la aparición del cable en 1975, el giro hacia el entretenimiento y la incorporación de las publicaciones locales a las grandes cadenas y grupos corporativos resultó en una creciente tendencia hacia el efectismo y hacia la inclusión de noticias basadas en rumorología local (Víctor, 1993). En muchas ocasiones se buscaba generar el miedo en el espectador y aumentar las audiencias gracias al tratamiento de temas tan morbosos como el satanismo o el asesino en serie.

La retransmisión de las imágenes de los abusos psicopáticos de los soldados en Vietnam recordó al nazismo y sus procedimientos ordinarios para perpetrar actos de crueldad (Murley, 2008), derivando en un nihilismo social y en un relato de degradación cultural a causa de la irracionalidad de estos actos. En consecuencia, el mayor sensacionalismo en los medios y la búsqueda de respuestas "racionales" conformaron los talk shows o programas de entrevistas y programas de debate, donde los 
talking heads o pseudoexpertos ofrecían explicaciones especializadas. Sin embargo, "no participan oficialmente en la investigación ni acceden a hechos del caso. [...] Suelen especular sobre el motivo de los asesinatos y las posibles características del criminal. Tales afirmaciones pueden mal informar a la audiencia y aumentar el miedo en una comunidad" (Morton, 2008: 43) .

La mezcla de fantasía y realidad de estos "expertos" junto con la divulgación de la recreación de los crímenes a través de los programas de True Crime Fiction como America's Most Wanted (20th Century Fox Television, Fox Productions, STF Productions, 1988-actualidad) resultó en la cosificación del asesino en serie (Ingebretsen, 1998) y reforzó la función de las autoridades para destruir a esta amenaza social. El conservadurismo de los ochenta acabaría por fortalecer aún más esta idea en favor de las explicaciones maniqueístas a los problemas sociales. La mezcla de todos estos relatos y la repetición de clichés en el cine de terror sirvieron para ampliar esta imagen a otras áreas del espacio público. La aparición del término, en consecuencia, visibilizó a un enemigo creado previamente y permitió a Reagan y sus simpatizantes culpabilizar a la permisividad progresista-hippies, movimiento por los derechos civiles- por la degradación cultural a la que se estaban enfrentando.

\section{Entender el cine de terror postclásico estadounidense}

El cine de terror sirvió como escenario de actuación del asesino en serie por las características propias del género. Por un lado, el miedo cinematográfico permite al espectador exponerse de manera catártica a cualquier peligro (Hanich, 2010). Por otro lado, su fórmula narrativa, basada en la oposición de dos conceptos, facilita la rápida comprensión de sus historias. A pesar del predominio de este esquema, el terror, tal y como demostró James B. Twitchell (1985), es un producto cultural inherente al contexto en que se produce. En consecuencia, en el caso estadounidense, la importancia del bien y el mal se acomoda a un esquema que opone a dos territorios enfrentados.

Por un lado, la normalidad abarca todo el espacio inserto dentro de los límites sociales y refleja sus reglas de funcionamiento. La naturalización de una comprensión del mundo aparentemente objetiva responde, tal como señala Norman Fairclough (1989), a la ideología del grupo dominante que, en nuestro caso, responde a una serie de valores surgidos de la misma cultura (Hume, 2002), entre los que se encuentran el sueño americano, la consideración del trabajo como camino al triunfo, la inocencia y la predestinación. Es por esta razón por la que los protagonistas siempre van a representar los ideales de belleza y de virtud a los que debe aspirar el público.

Frente a este concepto, la monstruosidad personifica todos aquellos elementos que son excluidos del discurso hegemónico. Por una parte, su existencia encarna, en palabras de Robin Wood (1986: 195), el regreso amenazante de lo reprimido y, por otro, la necesidad de defender el orden social que quedará ratificado por su presencia. Desde una perspectiva cultural, la frontera juega un papel esencial en el nacionalismo estadounidense al haber establecido una barrera mental de separación entre la civilización y la naturaleza salvaje (Slotkin, 2000). Al mismo tiempo, la división

\footnotetext{
"They have no official role in the investigation and no access to any of the intimate facts of the case. [...] They often speculate on the motive for the murders and the possible characteristics of the offender. Such statements can misinform the public and may heighten fears in a community". (Traducción de la autora)
} 
mental de espacio influyó en la ordenación jerárquica de todos los componentes de la sociedad.

La naturaleza subversiva del monstruo y el temor a unas consecuencias catastróficas refuerzan el funcionamiento del sistema hegemónico e interpelan al espectador a posicionarse a favor de los protagonistas y una necesaria separación. En consecuencia, las autoridades (policiales, médicas, etc.) deben ser las encargadas de clasificar e identificar al monstruo para salvaguardar a los ciudadanos de estas amenazas.

Atendiendo al desarrollo general del terror audiovisual, el éxito y la diversificación de su producción fueron los dos grandes rasgos de este periodo: por un lado, el rejuvenecimiento de las audiencias y la búsqueda de una mayor violencia en pantalla ayudan a comprender su éxito. Por otro lado, la creciente importancia del ocio juvenil y el abaratamiento tecnológico permitieron a un mayor número de cineastas plantear propuestas. La década de los sesenta vio nacer hitos del género como Psicosis (Psycho, Alfred Hitchcock, 1960), La semilla del diablo (Rosemary's Baby, Roman Polanski, 1968) o La noche de los muertos vivientes (Night on the Living Dead, George A. Romero, 1968) gracias a la desaparición de la censura oficial, el protagonismo creciente del sexo y la violencia o la producción independiente. El monstruo dejó de ser una criatura físicamente diferente para convertirse en una amenaza mucho más humana y gestada en el seno de la propia sociedad estadounidense (Duchaney, 2015).

La siguiente década, tal y como afirma Andrew Tudor (1989), se caracterizó por disfrutar de un gran éxito, gracias a su capacidad para llevar el miedo cinematográfico a un nivel mucho más intenso Su tratamiento más realista, corporal y sangriento aprovechó la aparición de nuevas cámaras mucho más baratas y ligeras. Además, la influencia de las corrientes extranjeras, la teoría de autor y la mayor experimentación se trasladaron también a este terreno (Cook, 1994). En este género, aparecieron nuevos movimientos independientes -el American Gothic reflejó de manera terrorífica los problemas del momento- y tendencias artísticas -David Cronenberg plantea una visión novedosa del cuerpo a través de la Nueva Carne-.

Los ochenta popularizaron un terror que banalizaba la violencia y eliminaba, en su mayor parte, la crítica social precedente (Prince, 2002). Desde una perspectiva industrial, la diversificación de mercados o las mini-majors -New Line Cinema, por ejemplo- fueron dos de los grandes rasgos de esta década. Además, las sagas y secuelas tomaron a personajes populares y explotaron su potencial hasta el agotamiento. A todo esto, se le sumó la aparición del vídeo, que permitió que numerosos directores amateurs consiguieran realizar sus películas con un presupuesto mucho más barato.

\section{La creación identitaria y fílmica del asesino en serie}

La presencia del monstruo humano en el cine de terror de la segunda mitad del siglo XX sirvió para, como se ha comentado, reafirmar un orden social (Tonkiss, 2004) que se erigía como un espacio homogéneo y cohesionado (Hall, 2003) exento de elementos disruptivos. Se trata de un antagonista paradigmático por su mezcla de elementos ficticios y realistas -tomado de delincuentes reales como John Wayne Gacy, Sam Berkowitz, etc. -, cuyos orígenes contemporáneos se sitúan en Jack el Destripador. El desconocimiento de su identidad facilitó la mitificación de sus crí- 
menes, así como un discurso de interclasismo misógino (Bloom, 2007), asentado en los diferentes sospechosos - un médico, un charcutero, un miembro de la familia real, etc. $-\mathrm{y}$ en la apertura del salvajismo y la brutalidad a cualquier hombre blanco urbano.

En el caso estadounidense, hemos observado una serie de categorías en una muestra de setenta títulos estrenados entre 1960 y 1980 con los siguientes resultados ${ }^{4}$ :

\begin{tabular}{lll}
\hline 1960-1980 & & \\
\hline Género del asesino individual & Masculino & 48 \\
\cline { 2 - 3 } & Femenino & 10 \\
\cline { 2 - 3 } & Grupal & 9 \\
\cline { 2 - 3 } & Desconocido & 3 \\
\hline Localización & Urbana & 44 \\
\cline { 2 - 3 } & Rural & 26 \\
\hline Final del asesino & Muerte & 41 \\
\cline { 2 - 3 } & Encierro/Sobrevive & 24 \\
\cline { 2 - 3 } & Desconocido & 5 \\
\hline Razones del comportamiento & Locura & 55 \\
\cline { 2 - 3 } & Otras & 15 \\
\hline Expertos & Sí & 40 \\
\cline { 2 - 3 } & No & 30 \\
\hline
\end{tabular}

Tabla 1. Análisis cuantitativo de sesenta películas de terror (1960-1980). [Fuente: elaboración propia]

Respecto al género, la naturalización masculina de este personaje parecería explicarse por los casos reales y la constante aparición de hombres con este perfil. Sin embargo, si nos paramos a analizar a las antagonistas femeninas observaremos que, en primer lugar, ocupan mayoritariamente trabajos relacionados con el cuidado: ama de llaves en Alice Sweet Alice (Alfred Sole, 1976), cocinera en Viernes 13 (Friday the 13th, Sam Cunningham, 1980) o camarera en The Gore Gore Girls, (Herschell Gordon Lewis, 1972). Asimismo, a excepción de la locura, la ambición y la eliminación de su posibilidad de cuidar son los dos motivos que explican sus conductas delictivas. En contraposición al hombre, la lujuria o la represión de los impulsos sexuales nunca ${ }^{5}$ se utilizan para explicar estos comportamientos. Así, se produce una estereotipación de la mujer ausente de deseo y encerrada en el papel doméstico que incide en la desigualdad del género (Zeisler, 2008).

En el caso masculino, su figura se vincula a un hombre blanco heterosexual, cuya represión sexual y sadismo sirven para acentuar los rasgos de este monstruo como se revela en Mundo Depravados (Herb Jeffries, 1967) o en Impulso Criminal (The Killing Kind, Curtis Harrington, 1973). Desde la perspectiva profesional, la diversidad encontrada en la muestra nos ha permitido reconocer varias tipologías predomi-

\footnotetext{
La recopilación completa se encuentra en la monografía escrita por la autora (Tiburcio, 2019: 131-137).

En el caso de Criminally Insane (Nick Millard, 1975) esta necesidad se asemeja a la gula.
} 
nantes: el artista, el marginado, el de clase trabajadora y el rural. El asesino en serie como artista aparece en películas como Scream Baby Scream (Joseph Adler, 1969) o El asesino del taladro (The Driller Killer, Abel Ferrara, 1979) y considera sus crímenes como obras de artes que pervivirán tras su desaparición (De Quincey, 2008). De hecho, esa misma significación impide el acceso a esta categoría a los individuos corrientes. La segunda tipología, el marginado, vive en una realidad totalmente diferente a la sociedad normalizada. Los exconvictos, como en Llama un extraño (When a Stranger Calls, Fred Walton, 1979), o los veteranos de guerra, como en My Friends Need Killing (Paul Leeder, 1976), entre otros, utilizan la violencia contra un entorno que no reconocen. Su incapacidad para adaptarse y su respuesta agresiva convierten a estos individuos en un peligro.

A continuación, encontramos una tercera donde el monstruo pertenece a la clase trabajadora. Bloodthirsty Butcher (Andy Milligan, 1970) o La última casa a la izquierda (Last House on the Left, Wes Craven, 1972) son películas que oponen la racionalidad de la clase media al salvajismo de los trabajadores. A pesar de la idea nacionalista del sueño americano, se observa un clasismo inherente a la cultura capitalista basado en el rechazo a la pobreza (Wray y Newizt, 1997). En la misma línea, la jerarquización geográfica sitúa al espacio rural y al sureño en una posición inferior a la ciudad y al norte. El analfabetismo, la brutalidad y la endogamia de los rednecks, backwoods o hillbillies se enfatiza en títulos como El día de la Madre (Mother's Day, Charles Kaufman, 1980) o Madman, el loco (Madman, Joe Giannone, 1981) que conforman, como señala Bernice Murphy (2013), un salvajismo identitario totalmente alejado de la normalidad hegemónica. Desde los setenta, esta imagen retrató críticamente los comportamientos retrógrados de una parte de Estados Unidos, por un lado, y creó un contradiscurso macabro del olvido gubernamental ante las penurias de un sector poblacional (Harkins, 2004), por otro. En el caso urbano, su capacidad de adaptación y ocultación se debía a la concepción de la ciudad como un lugar degenerado, donde el monstruo puede desaparecer en una multitud totalmente viciada (Schmid, 2005).

Finalmente, la nacionalidad y la etnia jugaron un papel esencial ya que, salvo en algunos casos como Blood Feast (Herschell Gordon Lewis, 1963) o Diario de un loco (Diary of a Madman, Reginald Le Borg, 1963), los antagonistas solían ser estadounidenses blancos, cuyo doble discurso criticaba y reforzaba el mismo orden social. Por un lado, la violencia ejercida contra sus víctimas simbolizaba los conflictos sociales en torno a la búsqueda de una mayor igualdad. Por otro lado, el retorcido privilegio de utilizar la violencia permitió al hombre blanco convertirse en una figura de poder.

Tal y como señala Etienne Balibar (1995), "la identidad nunca es una adquisición pacífica: se afirma como garantía contra la amenaza de aniquilación que puede estar representada por 'otra identidad' (una identidad extranjera) o por un 'borrado de identidades" " $(186)^{6}$. En resumen, aunque la alteridad es expulsada de la sociedad normativa, su poder vino acompañado de una misma jerarquización donde el hombre blanco es el privilegiado en la escala social. Desde el punto de vista histórico, la violencia masculina blanca había constituido una parte importante del discurso

\footnotetext{
"Identity is never a peaceful acquisition: it is claimed as a guarantee against a threat of annihilation that can be figured by 'another identity' (a foreign identity) or by an 'erasing of identities' (a depersonalization)". (Traducción de la autora)
} 
nacionalista, cuyo origen se fundamenta en la mitificación de la relación hostil entre los puritanos y el nuevo mundo (Slotkin, 2000). En consecuencia, su configuración como personificación del aumento de la criminalidad y la inseguridad le otorga un poder que le permite convertirse tanto en un monstruo moral en el cine slasher como en una crítica al sistema capitalista y al abuso de poder y la degeneración de la etnia blanca.

\section{La normalidad como configuradora del asesino en serie en el cine de terror}

El racionalismo ilustrado de la normalidad expulsó al impuro e insano asesino en serie de la sociedad hegemónica. Las autoridades debían ser, por tanto, las encargadas de proteger a la sociedad de esta poderosa amenaza (Tithecott, 2006). La transgresión de sus crímenes y su disposición a cometerlos le condenó a convertirse en una otredad, basándose en la idea de que el motor de sus actos no era la racionalidad sino sus impulsos más primarios (Halttunen, 1998). De hecho, los filmes de terror señalaron su alteridad a través de los extraños, psicopáticos y peligrosos comportamientos de, por ejemplo, Fuad Ramses en Blood Feast, Arthur Malcolm en Los ojos sin cabeza (The Headless Eyes, Kent Bateman, 1971), Ezra Cobb en Trastornado (Deranged, Jeff Gillen y Alan Ormsby, 1974) o Reno Miller en El asesino del taladro (The Driller Killer, Abel Ferrara, 1979). Todos estos villanos se configuraban en base a la singular relación entre la realidad y la ficción. Mientras que los personajes inventados retrataban muchos rasgos de los criminales, los biopics mezclaron los datos reales con los clichés del género como revela The Zodiac Killer (Tom Hanson, 1971). Además, las localizaciones naturales, las historias lineales y la ausencia de elementos sobrenaturales se confundieron con la propagación de estereotipos -sadismo, locura, etc. - en el terreno audiovisual y periodístico.

El reconocimiento fílmico del poder del monstruo se construyó también a través de la debilidad de las víctimas ante su presencia, simbolizando la fragilidad de la sociedad estadounidense. La audiencia era así interpelada mediante la similitud con las víctimas ${ }^{7}$ del filme y el contexto de inseguridad reinante en Norteamérica. Desde los sesenta se observó una transformación en el tratamiento de la violencia, de manera que, mientras que en Psicosis la escena de la ducha jugaba con la imaginación del espectador, películas como Terror al anochecer (The Town that Dreaded Sundown, Charles B. Pierce, 1976), La noche de Halloween (Halloween, John Carpenter, 1978) o, incluso, Pesadilla en Elm Street (Nightmare on Elm Street, Wes Craven, 1984), se recrearon en el detallismo de los crímenes. Así, el monstruo "convierte a sus víctimas y sus cuerpos en objetos de consumo, en productos, es decir, en cosas materiales no individuales e intercambiables que pueden ser producidas y consumidas de manera serial" (Lefebvre, 2005: 52).

El aumento de muertos en cada filme y su cosificación tuvo su máxima expresión en el cine slasher, cuyo mensaje conservador durante los ochenta (Rogin, 1987) sirvió para culpabilizar a los personajes por su comportamiento inadecuado -sexo

Entendemos por víctimas aquellos hombre y mujeres que se convierten en el objetivo del asesino en serie y, finalmente, acaban siendo acuchilladas, ahogadas, etc. por el asesino en serie.

8 "Turn their victims and their bodies into objects of consumption, into consumer things, that is, into interchangeable non-individual material things that can be produced and consumed serially" (Traducción de la autora) 
premarital, drogas, etc.- o por errores del pasado - la venganza del asesino-. La $\mathrm{Fi}$ nal Girl o chica que sobrevive se convirtió en un arquetipo esencial porque "no solo es la castidad lo que la salva; sino, por encima de todo, [...] su capacidad de encajar en el espíritu capitalista. [...] Para la ideología neoliberal lo más importante es ser competitivo" (Pérez Ochando, 2016: 132).

Respecto a las autoridades - policías, psiquiatras, criminólogos-y su poder disciplinario, jugaron un papel predominante como "sabio-experto" con un conocimiento especializado (Foucault, 1979). Mientras que en los sesenta fueron los encargados de resolver el conflicto como se puede observar en Psicosis o El estrangulador de Boston (The Boston Strangler, Richard Fleischer, 1968), a partir de los setenta aumentó la tendencia a presentarles ausentes o inútiles tal y como revelan La matanza de Texas (The Texas Chainsaw Massacre, Tobe Hooper, 1974) o Vestida para matar (Dressed to Kill, Brian de Palma, 1980). Desde una perspectiva histórica, las crisis sucesivas de los setenta - el escándalo Watergate, la guerra de Vietnam y actuaciones desproporcionadas del gobierno contra la población civil como la masacre de Kent State- habían cuestionado el prestigio social de unas autoridades corruptas e incapaces de detener la ola de violencia que asolaba Estados Unidos. Esta última tomó diferentes formas entre las que se encontraban un mayor índice de criminalidad y delincuencia (Lane, 1997), asesinatos -como los de Martin Luther King o John F. Kennedy- o atentados políticos -Nixon en 1974 o Ford al año siguiente- y la aparición de figuras como Charles Whitman ${ }^{9}$, Brenda Ann Spencer ${ }^{10}$ o los propios asesinos en serie.

A finales de la década, en medio de todo este caos, los thrillers de asesinos en serie y los filmes de terror volvieron a otorgar al experto una habilidad superior para resolver los casos. Según Isabel Santaularia se basaba en un "conocimiento especializado no solo necesario para llevar a la captura del criminal, sino también para acumular pruebas que puedan ser utilizadas para asegurar una sentencia judicial y el consecuente castigo del asesino una vez capturado" (2009: 109). En consecuencia, la imagen del especialista dibujó la retórica del héroe frente al villano, reflejando la concepción conservadora del mal como una desviación moral (Jenkins, 1994).

El azar y la casualidad suelen ser los principales motivos ${ }^{11}$ asociados al encuentro violento entre los protagonistas y el antagonista. Este enfrentamiento consiste, o bien, en la irrupción del grupo de protagonistas-víctimas en el territorio del asesino en serie como revela Pánico antes del amanecer (Just Before Dawn, Jeff Lieberman, 1981) o, bien, en la invasión por parte del asesino en serie del espacio de las víctimas, lo que se observa en Henry: retrato de un asesino (Henry: Portrait of a Serial Killer, John McNaughton, 1986). En ambos casos, el cuestionamiento de la predestinación puritana (Bremer, 2009) y el excepcionalismo retrataban un miedo cultural basado en la negación de la superioridad de la civilización estadounidense. Aunque el discurso alternativo tampoco parecía ofrecer una mejor alternativa, ya que el empoderamiento divino del monstruo le convertía en un ser elegido para poseer los mismos poderes que Dios.

\footnotetext{
En 1966 mató a quince personas e hirió a treinta y dos en un tiroteo desde la Universidad de Texas.

10 En 1979, esta adolescente de dieciséis años mató a dos personas e hirió a otras nueve en un colegio de primaria en San Diego, alegando que no le gustaban los lunes.

11 A partir de los ochenta, la venganza por algún error cometido por los protagonistas suele explicar las motivaciones de asesinos como Freddy Krueger, Jason Voorhees, etc.
} 
Volviendo a la doble naturaleza del encuentro, en el segundo caso predomina el monstruo urbano por su capacidad de camuflaje, cuya habilidad le eleva frente la peligrosidad del rural que se origina por su aspecto. En cambio, la irrupción de los protagonistas, representantes de la sociedad hegemónica, simboliza el traspaso de la frontera entre la civilización y el salvajismo, y su conversión en una otredad amenazante ajena a la normalidad salvaje y brutal que se encuentran. Su actitud altiva ante una comunidad que no comprenden reflejaba una serie de ansiedades culturales -la invasión de Vietnam, el descubrimiento de la pobreza rural- que enfrentaban al estadounidense ante su naturaleza imperialista.

En conclusión, la definición de territorios jugaba un papel fundamental en la construcción del "nosotros-normalidad" frente al otro. Sin embargo, esta monstruosidad, en función de su capacidad de amenaza y su poder, ocupaba un estrato más alto - capacidad de camuflaje, salvajismo, fuerza- en función de su consideración dentro de la escala social.

\section{La noche de Halloween: un hito en la construcción del monstruo y del criminólogo}

La noche de Halloween marca un punto de inflexión en la evolución del género y en el proceso de mitificación del monstruo. Existen, por tanto, varias razones que explican la elección de este caso de estudio para ilustrar la teoría previa. En primer lugar, siguiendo a David Cook (1994), se constituye como modelo del popular subgénero slasher, donde la humanidad del monstruo queda desterrada para convertirse en una máquina de matar enmascarada. Su uniformización mediante una vestimenta y un arma características acabó distinguiendo estas cintas de producciones previas y construyendo una categorización fílmica específica en torno a esta figura.

Desde una perspectiva histórica, la deshumanización del asesino en serie mediante la máscara y las habilidades sobrenaturales encarnó el sentimiento de inseguridad por una violencia que fue impregnando todos los rincones de la sociedad de finales de los setenta (Rathgeb, 1991). La sociedad estadounidense había sido testigo desde mediados de los cincuenta de una crisis de tipo social -contracultura, actos de grupos conservadores y de extrema derecha-, económica-crisis del petróleo de 1973, aumento de la inflación y del desempleo-, política -el escándalo Watergate, el asesinato político de John Fitzgerald Kennedy- y cultural -las cruentas imágenes de la guerra de Vietnam, el cuestionamiento de la superioridad de la clase media y el hombre blanco-. Por su parte, Haddonfield simboliza a esa clase media que, a pesar de haberse aislado físicamente en un mundo idealizado, se vio obligada a afrontar la extensión de un mal desconocido.

Finalmente, la presencia del doctor Loomis se constituye como la representación cinematográfica del criminólogo especialista que venía produciéndose desde principios de los setenta. De hecho, estas figuras habían conseguido un lugar en la memoria colectiva gracias a la captura de figuras tan mediáticas como John Wayne Gacy o Ted Bundy. Por tanto, aunque el psiquiatra no se presenta con estas características, su conocimiento especializado y su disposición a capturarle activamente refleja la aparición de estas figuras en el espacio público.

El argumento se centra en un grupo de jóvenes perseguidos por Michael Myers, un interno que escapa de un psiquiátrico y llega a Haddonfield (Illinois) en la noche 
de Halloween. Su psiquiatra, Samuel Loomis, le persigue hasta el pueblo con el objetivo de capturarle y encerrarle. Desde una perspectiva fílmica, este filme sentó las bases del enfrentamiento entre un asesino en serie, que se construye a través de sus víctimas, y un experto -psicólogo/criminólogo-, donde ambas conforman un relato mítico abierto a la presencia de elementos sobrenaturales en el monstruo.

La maldad de Myers se establece desde el principio a través de una narración voyeur de sus asesinatos, el uso de planos subjetivos de la steadicam y sus respiraciones sin rostro (Muir, 2002). Así, el rápido reconocimiento de su monstruosidad a través de su psicopatía, su ausencia de culpa y de lenguaje, y su incapacidad para reintegrarse en la sociedad conectó con el creciente discurso maniqueo del conservadurismo de finales de los setenta (Skal, 2002). De hecho, la máscara blanca del capitán Kirk (Star Trek, Paramount Television Studios, 1966-1969), representativa de los valores contraculturales de los sesenta, y el mono azul de mecánico, característico de la clase trabajadora, insistían en la alteridad de estos grupos frente a una normalidad hegemónica de clase media blanca. El violento regreso de Michael a Haddonfield obligaba a afrontar la vuelta a un pasado repleto de episodios violentos -la guerra de Vietnam, la masacre de Kent State, el asesinato de Martin Luther King, el de Robert Kennedy, etc.- que aumentaba la intranquilidad de la clase media blanca por su pasividad cómplice (Bergland, 2000).

Sus habilidades sobrehumanas -infalible en la caza, gran fuerza, etc.- y sobrenaturales -inmortalidad-, totalmente novedosas en estos relatos, coincidían con el discurso mediático que convertía a los asesinos en serie en auténticas celebridades (Wiest, 2011). La creación de estereotipos repetidos en torno a estos criminales los convirtió en las ramificaciones de un discurso que incidía en la inseguridad ciudadana y la inefectividad de un sistema que, en lugar de acabar con esta figura, se mostraba impotente ante la aparición de nuevos asesinos que sustituían a los que encarcelaban. En consecuencia, la inmortalidad de Myers simbolizaba la deshumanización de estas figuras a través de su categorización y la perpetuación del homicidio en serie a lo largo del tiempo.

El filme vincula además este discurso a la leyenda urbana a través de un relato que avanza desde un acontecimiento pasado traumático -el asesinato de Judith Myers- hasta la fuga y la masacre de Michael Myers. La confluencia de fantasía y realidad convierten al espacio cinematográfico en un lugar "donde el peligro acecha a la cotidianidad y las crueles coincidencias toman dimensiones cósmicas" (Leeder, 214: 21-22) ${ }^{12}$. La fecha de Halloween añade entonces un significado simbólico a una noche que se impregna de la sobrenaturalidad (Rogers, 2002), de manera que el propio vínculo entre Michael y el bogeyman u "hombre del saco" conecta rápidamente con el terreno de lo divino y lo diabólico arraigados en el folklore (Gilmore, 2003). Lo demoniaco toma forma humana, desenterrando el recelo puritano a la posible omnipotencia del mal y conectando con el conservadurismo de finales de los setenta.

Frente a Myers, el doctor Samuel Loomis se posiciona sobre la autoridad del sheriff Beckett al ser la única autoridad psiquiátrica capaz de capturar y predecir el comportamiento del antagonista. De hecho, el discurso de la monstruosidad de Michael descansa sobre un diagnóstico que refuerza la naturaleza anormal de la locura,

12 "Where danger lurks within the everyday and cruel coincidences take on cosmic dimensions". (Traducción de la autora) 
marginándola fuera de los límites de la sociedad normalizada (Hall, 1991). En este sentido, es importante destacar que la decisión del doctor de suministrarle torazina a pesar de las críticas por sus efectos (Whitaker, 2002) se demuestra acertada tras la huida del asesino, quien ha conseguido evitar ingerirlas. Así, su autoridad no solo se refleja en las aseveraciones que profiere sino en sus propios actos que revelan un conocimiento muy superior del sujeto.

Loomis incorporaba a la cultura popular la figura del criminólogo quien, desde la aparición de la Unidad de Ciencias del Comportamiento en 1972 (FBI, 2008), se había convertido en un elemento clave para proteger a la sociedad de los temibles asesinos en serie. Cabe recordar que la peligrosidad de estos últimos descansa en la incomprensión social de unos crímenes carentes de motivación económica (Ressler y Shachtman, 1992), lo que suponía un ataque a la seguridad ciudadana y a la propia justificación capitalista de la violencia como medio para obtener un mayor beneficio.

Así, el elemento principal con el que cuenta el psiquiatra para enajenar a Michael es su cosificación a través de varios métodos como la utilización del pronombre neutro it en lugar del masculino he o him o la afirmación de que no es humano por su incapacidad para socializar a causa de su aislamiento continuado (Rathgeb, 1991). La inexistencia de una cura que permita su reintegración sirve al psiquiatra para reafirmar su inhumanidad a través de su maldad - tras la huida de Michael del psiquiátrico, se refiere a él afirmando "la maldad se ha ido"- o sus aseveraciones -le asegura a Beckett que su paciente "no es un hombre"-. A lo largo del filme, su diagnóstico se ve reforzado por el apelativo Bogeyman que utilizan los personajes Tommie o Laurie para referirse al asesino. La conversación final mantenida entre esta última y el doctor resulta esclarecedora, donde ella afirma que "era el Bogeyman" y Loomis le contesta "de hecho, lo era".

Desde el punto de vista histórico y fílmico, la amenaza que representa Michael por ser capaz de aniquilar a cualquier ser vivo (Muir, 2002) refleja la visión conservadora de una sociedad totalmente abocada a su destrucción. La retórica de la decadencia basada en que el orden y la racionalidad estaban cediendo espacio a la barbarie y al desorden conforma al asesino en serie como la personificación de una transgresión imperdonable (Ingebretsen, 1998). En el filme, la deshumanización y la sobrenaturalidad del asesino enmascarado queda remarcada por la enorme destrucción que acompaña a su libertad. Así, la indefensión social ante este poderoso elemento refuerza el papel vigilante y protector del psiquiatra, situándose en una posición de oposición frente al villano. La mitificación del saber del psiquiatra y la sobrenaturalidad de ambos encarna ese relato de lucha conservadora donde el héroe debe enfrentarse a un villano que debe ser destruido.

En conclusión, La noche de Halloween se conformó como un texto de terror que reconstruye las barreras separadoras entre la normalidad y la monstruosidad. La deshumanización de Michael Myers y sus atributos sobrehumanos convierten a esta figura en un ser desconocido que necesita ser explicado por un experto. Desde una perspectiva histórica, ese mismo proceso se había producido desde los medios de comunicación y un término criminológico que encapsuló a todos los individuos en una misma categoría. 


\section{Conclusiones}

A lo largo de este artículo hemos reflexionado sobre la naturaleza cultural e histórica del asesino en serie. La construcción de su discurso surge de la confluencia de diferentes relatos como la criminología, el cine de terror o los medios de comunicación que señalaron su peligrosidad por su comportamiento antisocial. La mezcla entre la realidad y la ficción facilitaron la asociación repetida de una serie de estereotipos que reforzaron su deshumanización.

En este proceso, además del cine de terror, hubo dos elementos fundamentales que sirvieron para construir su alteridad: por un lado, la aparición en programas sensacionalistas de los talking heads incidió en la estereotipación del asesino en serie como un monstruo; por otro lado, la aparición del término conllevó a la creación de perfiles que categorizaban sus comportamientos en base a sus crímenes y eliminaban sus diferencias individuales. En ambos casos, estos individuos se convirtieron en un relato de perversión, crimen y sadismo que desautorizaba cualquier tipo de empatía hacia un ser humano que había visto su condición degradada por sus propios impulsos.

El empoderamiento que alcanzó el asesino en serie por su capacidad de amedrentar a la sociedad no escapó de la lógica hegemónica y tuvo como resultado la creación de un espacio antagónico con un orden jerárquico similar que naturalizaba al hombre blanco heterosexual y urbano como una figura de poder. Frente a esta amenaza, el criminólogo, como especialista, se convierte en una figura necesaria para salvaguardar a una sociedad asediada por el miedo a la violencia creciente y la inseguridad.

El cine de terror reflejó estas mismas ideas a través de la asociación del monstruo con un hombre blanco y urbano principalmente, cuyas habilidades son superiores al antagonista femenino o rural. En este terreno, La noche de Halloween se convierte en un título esencial para comprender el giro hacia el conservadurismo de finales de los setenta. Así, la mitificación del asesino en serie y su conversión en leyenda urbana viene acompañada del experto quien, en su papel de "héroe" especializado, se enfrenta y protege a la sociedad desvalida. La popularización del término en los años ochenta continuará con esta misma tendencia hasta la irrupción del cine indie y la hibridación de géneros, donde el monstruo postmodernista se adapta a una sociedad donde las barreras entre el bien y el mal estarán totalmente difuminadas.

Finalmente, la naturaleza cultural del monstruo exige la necesidad de ampliar los límites disciplinares y, desde la perspectiva de la historia cultural, acceder a un escenario mucho más plural donde los medios de comunicación o los estudios semióticos ofrecen nuevas perspectivas sobre el periodo contemporáneo. El cine de terror, debido a su categoría popular y su búsqueda del beneficio rápido, se convierte en una fuente idónea de estudio, al asociar a sus protagonistas y antagonistas una serie de características que reflejaban las ansiedades sociales.

\section{Bibliografía}

AAVV. (2013). Crime Classification Manual. A Standard System for Investigating and Classifying Violent Crime. Third Edition. Hoboken: Wiley. 
Altman, R. (2000). Los géneros cinematográficos. Barcelona: Paidós.

Balibar, E. (1995). "Culture and Identity”. En John Rajchman (ed.), The identity in Question. Nueva York, Londres: Routledge, 173-194.

Bergland, R. (2000). The National Uncanny. Indian Ghosts and American Subjects. Hanover: University Press of New England.

Bloom, C. (2007). "The Ripper Writing: A Cream of a Nightmare Dream". En Alexandra Warwick y Martin Willis. (eds.), Jack the Ripper. Media, Culture, History. Manchester: Manchester University Press, 159-177.

Bremer, F. J. (2009). Puritanism. A Very Short Introduction. Oxford: Oxford University Press.

Cook, D. A. (1994). Lost Illusions. American Cinema in the Shadow of Watergate and Vietnam, 1970-1979. Berkeley: University of California Press.

De Quincey, T. (2008). Del asesinato considerado como una de las bellas artes. Sevilla: Espuela de Plata.

Duchaney, B. N. (2015). The Spark of Fear. Technology, Society and the Horror Film. Jefferson: McFarland \& Company.

Fairclough, N. (1989). Language and Power. Nueva York: Longman.

Fairclough, N. (1998). "Political Discourse in the Media: An Analytical Framework". En Allan Bell y Peter Garrett (eds.). Approaches to Media Discourse. Oxford, Malden: Blackwell Publishers, 142-162.

FBI. (2008). “The FBI. A Centennial Story, 1908-2008”. Recuperado de https://www.fbi. gov/about-us/history/a-centennial-history/the-fbi-a-centennial-history-1908-2008 (Fecha de acceso: 02/03/2020)

Foucault, M. (1979). Microfísica del poder (Genealogía del poder). Madrid: La Piqueta.

Gilmore, D. D. (2003). Monsters. Evil Beings, Mythical Beasts, and All Manner of Imaginary Terrors. Filadelfia: University of Pennsylvania Press.

Hall, S. (2003). "The Spectacle of the 'Other'”. En Stuart Hall (ed.), Representation: Cultural Representation and Signifying Practices. Londres: Sage, the Open University, 223-290.

Halttunen, K. (1998). Murder Most Foul. The Killer and the American Gothic Imagination. Cambridge: Harvard University Press.

Hanich, J. (2010). Cinematic Emotion in Horror Films and Thrillers. The Aesthetic Paradox of Pleasurable Fear. Nueva York: Routledge.

Harkins, A. (2004). Hillbilly. A Cultural History of an American Icon. Oxford: Oxford University Press.

Holmes, R. M. y de Burger, J. (1988). Serial Murder. Newbury Park: Sage.

Hume, K. (2002). American Dream, American Nightmare. Fiction Since 1960. Chicago: University of Illinois Press.

Ingebretsen, E. J. (1998). "The Monster in the Home: True Crime and the Traffic in Body Parts". Journal of American Culture, vol. 21, núm. 1, 27-34. https://doi.org/10.1111/ j.1542-734X.1998.2101_27.x

Jenkins, P. (1994). Using Murder. The Social Construction of Serial Homicide. Nueva York: Aldine de Gruyter.

Lane, R. (1997). Murder in America: A History. Columbus: Ohio State University Press.

Leeder, M. (2014). Halloween. Leighton Buzzard: Auteur.

Lefebvre, M. (2005). "Conspicuous Consumption: The Figure of the Serial Killer as Cannibal in the Age of Capitalism”. Theory, Culture \& Society, vol. 22, núm. 3, 43-62. https:// doi.org/10.1177/0263276405053719 
Martín Alegre, S. (1997). More Human Than Human: Aspects of Monstrosity in the Films and Novels in English of the 1980s and 1990s. Tesis doctoral. Barcelona: Universitat Autònoma de Barcelona. Recuperado de http://www.tdx.cat/TDX-0615109-182044

Morton, R. J. (2008). "Serial Murder: Multi-Disciplinary Perspectives for Investigators". Recuperado de https:/www.fbi.gov/file-repository/stats-services-publications-serial-murder-serial-murder-july-2008-pdf (Fecha de acceso: 28/02/2020).

Muir, J. K. (2002). Horror Films of the 1970. Jefferson: McFarland \& Company.

Murphy, B. M. (2009). The Suburban Gothic in American Popular Culture. Basingstoke: Palgrave Macmillan.

Murphy, B. M. (2013). The Rural Gothic in American Popular Culture. Backwoods Horror and Terror in the Wilderness. Basingstoke: Palgrave Macmillan.

Murley, J. (2008). The Rise of True Crime: 20th-Century Murder and American Popular Culture. Westport: Praeger.

Pérez Ochando, L. (2016). Todos los jóvenes van a morir. Ideología y rito en el Slasher Film. Murcia: Micromegas.

Prince, S. (2002). A New Pot of Gold Hollywood Under the Electronic Rainbow, 1980-1989. Berkeley: University of California Press.

Rathgeb, D. L. (1991). "Bogeyman from the Id: Nightmare and Reality in Halloween and $A$ Nightmare on Elm Street". Journal of Popular Film \& Television, vol. 19, núm. 1, 36-43. https://doi.org/10.1080/01956051.1991.9944106

Ressler, R. K. y Shachtman, T. (1992). Whoever Fights Monsters. Londres: Simon \& Schuster.

Rogin, M. P. (1987). The Movie and Other Episodes in Political Demonology. Berkeley: University of California Press.

Santaularia, I. (2009). El monstruo humano. Una introducción a la ficción de los asesinos en serie. Barcelona: Laertes.

Schmid, D. (2005). Natural Born Celebrities. Serial Killer in American Culture. Chicago: The University of Chicago Press.

Skal, D. (2002). Death Makes a Holiday. A Cultural History of Halloween. Nueva York: Bromsbury.

Slotkin, R. (2000). Regeneration through Violence. The Mythology of the American Frontier, 1600-1860. Norman: University of Oklahoma Press.

Stokes, J. (2013). Ho to Do Media and Cultural Studies. Los Angeles: Sage.

Thomson, D. (2009). The Moment of Psycho. How Alfred Hitchcock Taught America to Love Murder. Nueva York: Basic Books.

Tiburcio, E. (2019). Y nació el asesino en serie. El origen cultural del monstruo en el cine de terror estadounidense. Madrid: Los libros de la Catarata.

Tithecott, R. (2006). "Investigating the serial Killer: the Seeking of Origins". En P. David Marshall (ed.), The Celebrity Culture Reader. Nueva York: Routledge, 443-453.

Tonkiss, F. (2004). "Analysing Text and Speech: Content and Discourse Analysis”. En Clive Seale (ed.) Researching Society and Culture. Londres: Sage, 367-382.

Tudor, A. (1989). Monsters and Mad Scientists: A Cultural History of the Horror Movie. Cambridge: Basil Blackwell.

Twitchell, J. B. (1985). Dreadful Pleasures. An Anatomy of Modern Horror. Oxford: Oxford University Press.

Victor, J. S. (1993). Satanic Panic. The Creation of a Contemporary Legend. Chicago: Open Court.

Vidal Coy, J. L. (2010). Periodismo y censura en las guerras ultramarinas de EEUU en el siglo XX. Murcia: Universidad de Murcia. 
Whitaker, R. (2002). Mad in America. Bad Science, Bad Medicine, and the Enduring Mistreatment of the Mentally Ill. Cambridge: Perseus.

Wiest, J. B. (2011). Creating Cultural Monster. Serial Murder in America. Boca Raton: CRC Press.

Wood, R. (1986). Hollywood. From Vietnam to Reagan. Nueva York: Columbia University Press.

Wray, M. y Newitz, A. (eds.) (1997). White Trash. Race and Class in America. Nueva York: Routledge.

Zeisler, A. (2008). Feminism and Pop Culture. Berkeley: Seal Press. 